\title{
A TUTELA DAS MINORIAS PARLAMENTARES BRASILEIRAS COMO MEIO DE FOMENTAR A DEMOCRACIA
}

\section{Osmar Veronese ${ }^{1}$}

\begin{abstract}
Resumo
A história do Parlamento ocidental possui na relação das maiorias com as minorias uma de suas características fundamentais e, ao mesmo tempo, uma inesgotável fonte de atritos. Não há dúvida que a democracia se sustenta sobre o princípio majoritário, mas é preciso vigilância constante para combater os perigos das maiorias, evitando que elas se transformem em tirânicas, pois assim agindo sufocam as divergências e impedem o surgimento e fortalecimento de novas ideias, eventualmente representativas de minorias sociais. Inúmeras passagens legislativas, presentes em todas as esferas federativas brasileiras, na União, nos Estados, no Distrito Federal e nos Municípios, garantem espaços de atuação dos partidos e grupos minoritários, em proposta democrática que o presente artigo, a partir de amostras, dá ênfase. Em suma, o Brasil possui base legislativa suficiente para proteger a atuação das minorias parlamentares, presente desde às Câmaras de Vereadores até o Senado Federal, mas é imprescindível que a lei tenha projeção na vida real, pois tutelar essas minorias é, em última análise, preservar a democracia, mantendo no horizonte o sendero luminoso do porvir... democrático!
\end{abstract}

Palavras-chave: Parlamento. Democracia. Minorias Parlamentares.

\section{INTRODUÇÃO}

O Estado Constitucional vertente da Revolução Francesa de 1789 encontra no Parlamento seu berço e seu núcleo. Praticamente todas as instituições que caracterizam esse modelo de democracia ocidental, nos últimos duzentos anos, são produtos do Parlamento. Além disso, das grandes mudanças experimentadas nesse período, as assembleias não só têm sido testemunhas, mas protagonistas. Por isso, em meio a um turbilhão de críticas projetadas sobre as câmaras legislativas mundo afora, nunca é demais lançar um olhar compreensivo, sem a pretensão de apagar as alfinetadas, muitas vezes justas, mas de potencializar o debate pensando em auxiliar sua sobrevida em modelos de sociedade muito diversos daqueles existentes há dois séculos.

Uma das preocupações centrais dos estudiosos do sistema democrático é estabelecer as regras de relacionamento entre maiorias e minorias parlamentares. Se de um lado, não se pode negar que a democracia é governo da maioria, por outro, em respeito ao princípio da igualdade entre os cidadãos, a representação das

\footnotetext{
${ }^{1}$ Doutor em Direito Constitucional, pela Universidade de Valladolid, ES. Professor de Direito Constitucional (Graduação e Mestrado) da Universidade Regional Integrada do Alto Uruguai e das Missões (URI - Campus Santo Ângelo) e na graduação do Instituto Cenecista de Ensino Superior de Santo Ângelo (IESA).E-mail: osmarveronese@gmail.com
} 
minorias não pode ser calada ou submetida a toda a espécie de alijamento, sem que haja mecanismos de correção capazes de delimitar espaços e funções adequadas aos representantes dos diversos grupos componentes de sociedades plurais.

Este artigo pretende dar visibilidade a previsões constitucionais e legais brasileiras com potencialidade de tutelar os direitos das minorias parlamentares, ponto fundamental para, em passo adiante, estudar o aumento do protagonismo do Judiciário, a jurisprudência atual sobre o tema e até identificar um possível "estatuto das minorias parlamentares".

\section{SOBRE MAIORIAS E MINORIAS PARLAMENTARES EM EVOLUÇÃO}

O modelo democrático representativo assenta-se sobre a regra da maioria, a qual possui como tarefa nuclear a preservação das liberdades individuais e, noutra face, quando a restrição a esse valor for imprescindível, melhor que se imponha por decisão dos representantes do povo. Essa dúplice atuação da maioria, como garantidora ou limitadora das liberdades, justifica-se na medida em que os representantes do povo são os depositários dos mandatos para a adoção de uma decisão legítima.

A possibilidade de subtração da liberdade humana quando inserta em um contrato social, defendida por Rousseau, parece inspirar o modelo das democracias representativas ${ }^{2}$, com ao menos duas grandes vantagens: a primeira, é que essa semente é cultivada no ventre da democracia, e não na aristocracia da época do autor; a segunda, diz respeito a noção de liberdade, a qual muda radicalmente no tempo e no espaço. Tudo o que existia antes dos últimos duzentos anos, época da edificação dos institutos liberais democráticos, precisa ser relido. Embora os possíveis abusos ainda assombrem a democracia moderna, a guilhotina já não é mais a regra de tratamento dispensada à oposição, e muitos meios de perseguição sistemática dos adversários foram perdendo força.

As garantias construídas a partir do Parlamento e em seu favor, como foram as liberais, não se confundem com as concessões reais medievais, espécies de doação a título precário, resgatáveis a qualquer momento, ou melhor, a todo o momento em que vontade do soberano fosse afrontada. Em outras palavras, as apontadas imunidades medievais estavam muito mais a serviço dos monarcas do que da independência parlamentar.

Quanto mais distante o antecedente, mais frágil o laço genético com o modelo atual das prerrogativas, não tanto pela semelhança formal, maior ou menor, da previsão normativa, mas pela diversidade de contextos em que ele se apresenta. Uma coisa é ser livre na Antiguidade, outra é ser livre na Idade Média, e outra bem distinta é ser livre entre os modernos e contemporâneos. $\mathrm{O}$ eco e a garantia da liberdade entre estes, parlamentares ou não, com todos os percalços possíveis, são infinitamente maiores do que foram em outros tempos. Essa metamorfose refletida mormente

${ }^{2}$ APPIO, Eduardo. Direito das minorias. São Paulo: Revista dos Tribunais, 2008, p. 35. 
no âmbito estatal tempera os institutos no caldo cultural de seu tempo.

As maiorias do passado, na Grécia, Roma e, especialmente na Idade Média, não raramente eram conseguidas pela força das armas, ${ }^{3}$ se não um "bom argumento", ao menos algo convincente em especial aos destituídos delas. Na era dos direitos fundamentais alicerçados em um modelo de distribuição de poder que se pretende democrático, insertos na sociedade da informação, embora não ignorando a ameaça real e simbólica das armas, nutre-se profunda convicção de que o diálogo e as regras sejam as fórmulas adequadas para enfrentar os conflitos inerentes a qualquer sociedade, os quais se revelam mais intensos em sociedades multiculturais como a brasileira.

Quando Aristóteles, na Política, descreve a regra da maioria como um instrumento compatível com qualquer forma pura de governo, outorgando validade à deliberação, na medida em que ela decorre da intervenção de cidadãos livres e iguais, pois todos eles tomam parte dos assuntos públicos, não estava indicando a aceitação da opinião majoritária (nas situações de não consenso) por sua operatividade, mas por sua justiça, por vulnerar o menor número possível de direitos singulares e por assegurar o melhor juízo, o da maioria dificilmente corruptível. ${ }^{4}$

No início do pensamento liberal, a ideia de que a vontade da maioria dos integrantes de determinada comunidade, normalmente representada nas decisões do Parlamento, "naturalmente" unânime, era algo incontrastável. A aquiescência em fazer parte do pacto pressupunha verdadeira diluição da vontade minoritária ou sua integração na decisão da "maioria" do povo, representada no Parlamento (eventualmente até expressando a vontade de Deus), e as possíveis dissidências eram sinônimo de facção ou traição ${ }^{5}$,

Na sociedade contemporânea, nos frequentes debates acalorados produzidos no ventre das câmaras ocidentais, essa terminologia ainda é empregada com certa frequência, todavia, seu efeito não é mais o mesmo. Quer dizer, o fato de se estabelecer dissidência parlamentar, como sintoma de representação de uma sociedade complexa, não mais é sinônimo de traição, tampouco pressupõe o apagamento da diferença pela unanimidade. Ao contrário, esse é um fenômeno legalmente previsto, politicamente defensável e, em certas ocasiões, algo desejável para espelhar a diversidade e combater o imobilismo que a unanimidade pode produzir.

\section{A DEMOCRACIA ANCORADA NA MAIORIA}

A proposta democrática-liberal, que muitas facetas adotou mundo afora, expandiu-se calcada no

\footnotetext{
${ }^{3}$ REQUEJO, Paloma. Democracia parlamentaria y principio minoritario: la protección constitucional de las minorías parlamentarias. Barcelona: Ariel Derecho, 2000, p. 15.

${ }^{4}$ ARISTÓTELES apudREQUEJO, Paloma. Democracia parlamentaria y principio minoritario: la protección constitucional de las minorías parlamentarias. Barcelona: Ariel Derecho, 2000, p. 11.
} 
princípio majoritário. Cuida-se do verdadeiro combustível desse modelo de distribuição de poder, cujas contribuições para a democracia universal são inestimáveis. Não se pretende, assim, apagar a história, tampouco negar sua importância para o aperfeiçoamento da democracia hodierna, mas apenas apontar sua necessária reconfiguração.

O princípio da maioria absoluta, ou ainda mais de uma maioria qualificada pode constituir um caminho mais adequado para a ideia de liberdade, porque indica uma certa tendência à unanimidade na formação da vontade coletiva. O sistema ideal de liberdade significa a formação da vontade coletiva com uma maior aproximação possível da vontade dos indivíduos, ou seja, quando houver maior identidade entre vontades individuais com a vontade coletiva, mais próximo se estará de alcançar o máximo valor da liberdade. A maioria, assim, no sentido aqui tomado, sinaliza para decisões alinhadas ao maior número de sujeitos possíveis e em desacordo com o menor. Longe do império absoluto (ou ditadura) da maioria sobre a minoria, a vontade coletiva resulta de influências recíprocas entre ambos (ou vários) os grupos, como consequência do choque de suas intenções políticas, sobrevindo, com base no princípio da transação (claramente presente no procedimento parlamentar, com sua técnica, suas controvérsias dialéticas, discursos e réplicas...), uma linha média entre os interesses opostos como resultante da pugna sustentada pelas forças sociais. ${ }^{6}$

O princípio democrático guarda estreita vinculação com o princípio majoritário, que por sua vez deita raízes nos princípios da igualdade democrática, da liberdade e da autodeterminação. A conjugação desses princípios indica que a vinculação a uma determinada ordenação jurídica pressupõe, pelo menos, a concordância da maioria. Indivíduos livres e iguais possibilitam, mediante voto livre e igual, a adoção "de um método político de decisão que, pelo menos, beneficia de uma legitimidade quantitativa maioritária"”

Embora a democracia ainda possa ser tomada como o ponto de equilíbrio, entre direita e esquerda, para o qual o pêndulo político deve voltar, ${ }^{8}$ não parece satisfatória a adoção dessa fórmula de pacificação baseada na dualidade de classes para explicar as relações sociais de uma sociedade complexa que se potencializam nas decisões do parlamento.

O desafio de viver a democracia, hoje, pressupõe a inserção em um contexto no qual convivem vários subsistemas sociais em crescente diferenciação, com a autonomia de antigas esferas normativas, como as da moralidade, eticidade e religião, em uma sociedade acolhedora do pluralismo razoável de formas de vida e de visões de mundo não fundamentalistas, cujos desacordos inevitáveis podem ser tomados como plausíveis e assim

${ }^{5}$ REQUEJO, Paloma. Democracia parlamentaria y principio minoritario: la protección constitucional de las minorías parlamentarias. Barcelona: Ariel Derecho, 2000, p. 20.

${ }^{6}$ KELSEN, Hans. Esencia y valor de la democracia. Granada: Comares, 2002, p. 66-67.

${ }^{7}$ CANOTILHO, J. J. Gomes. Direito Constitucional e teoria da Constituição. Coimbra: Almedina, 1999, p. 456.

${ }^{8}$ KELSEN, Hans. A Democracia. São Paulo: Martins Fontes, 2000, p. 78. 
buscarem concorrentemente o reconhecimento de sua dignidade. ${ }^{9} \mathrm{O}$ princípio da democracia constitucional hodierna pressupõe o alargamento do que se entende por esfera pública política, não restrita aos fóruns oficiais do Estado, mas abarcando uma sociedade civil diversa daquela definida por Hegel e Marx, "formada por grupos, movimentos, associações e organizações sociais que se diferenciam tanto da esfera governamental, quanto do mercado, e que visam à dramatização e problematização de temas e problemas que dizem publicamente respeito aos diversos âmbitos da sociedade”. ${ }^{10}$ É esse o modelo da sociedade brasileira que se focaliza aqui, tendo na proteção das minorias um ingrediente essencial, consoante se explicita adiante.

\section{TUTELAR A MINORIA É PRESERVAR A DEMOCRACIA}

O casamento entre democracia e maioria é uma realidade histórica cujo divórcio está fora de cogitação, mas para que essa relação permaneça em harmonia com o passo do nosso tempo, há de ser temperada pela presença atuante das minorias. A verdadeira democracia pressupõe que se assegure às minorias o exercício de oposição institucionalizada, com garantia de seus direitos de dissenção, crítica e veiculação de sua pregação, de usar de todos os meios democráticos para tentar chegar ao governo, cuja alternância do poder seja uma possibilidade juridicamente assegurada, condicionada só a mecanismos políticos dependentes da opinião pública. ${ }^{11}$ Daí a necessidade de proteção do direito de opinião, de pensamento, de crença, de associação, de informação, etc, estendidos ao plano da cidadania, sem restrições irrazoáveis. A Constituição democrática deve garantir os direitos das minorias e impedir a prepotência, o arbítrio, a opressão contra elas, estabelecendo mecanismos que proporcionalmente representem os diversos pensamentos componentes da sociedade. ${ }^{12}$

O poder exercido por uma maioria democrática diferencia-se não apenas pela existência de oposição, mas pelo reconhecimento de sua legitimidade política, criando-se instituições que garantam um mínimo de possibilidade de existência e ação a distintos grupos religiosos, nacionais ou econômicos, quando constituídos por uma minoria de pessoas. ${ }^{13} \mathrm{~A}$ democracia necessita de continuada tensão entre maioria e minoria, em processo dialético elaborador da vontade política. A democracia é discussão, é transação, é compromisso, preferindo este

${ }_{9}^{9}$ OLIVEIRA, Marcelo Andrade Cattoni de. Comentários à Constituição do Brasil (Org. CANOTILHO, J. J. Gomes, et al). São Paulo: Saraiva/Almedina, 2014, p. 138-139.

${ }^{10}$ OLIVEIRA, Marcelo Andrade Cattoni de. Comentários à Constituição do Brasil (Org. CANOTILHO, J. J. Gomes, et al). São Paulo: Saraiva/Almedina, 2014, p. 139.

${ }^{11}$ Um governo democrático é, por definição, um governo de maioria limitado pelo respeito devido à minoria, com mecanismos de tutela (de segurança intrínseca do sistema democrático) ancorados em duas razões principais: o controle do poder governamental, a ser garantido inclusive por parte da minoria, e a possibilidade ou estímulo para que, em eleições futuras, a minoria possa se transformar em maioria (MANZELLA, Andrea. Il Parlamento. Bologna: Il Mulino, 1977, p. 211).

${ }^{12}$ ATALIBA, Geraldo. Judiciário e minorias. Revista de Informação Legislativa, Brasília, n. 96, 1987, p. 191.

${ }^{13}$ Importa reconhecer que a oposição há de ser exercida não apenas face à maioria parlamentar, mas também em face do governo, além de se viabilizar a oposição extraparlamentar, conectando-a ao direito fundamental de reunião, de manifestação e ao princípio democrático, sob pena de aqueles sem representantes parlamentares terem sua liberdade política restringida (CANOTILHO, José Joaquim Gomes. Direito Constitucional e teoria da Constituição. Coimbra: Almedina, 1999, p. 309). O presente estudo foca vol.09, nº. 04, Rio de Janeiro, 2016. pp. 2390-2405 2394 
procedimento e preterindo a imposição violenta da vontade do grupo dominante aos adversários. ${ }^{14}$

Não há dúvida que o sistema democrático ancora-se no princípio da maioria, ${ }^{15}$ o que não significa "absolutismo da maioria", mas exercício de seu direito em concorrência com o direito das minorias. A maioria não pode dispor de toda a "legalidade", tornando disponível o que é indisponível, como pode ocorrer com os direitos e garantias e com a disciplina constitucionalmente fixada. As maiorias qualificadas exigidas para determinados temas têm por escopo não apenas preservar a qualidade da decisão, mas proteger as minorias. Noutro enfoque, há limites internos ao princípio majoritário, pois embora represente a possibilidade de suas decisões se tornarem vinculativas por serem sufragadas por um maior número de cidadãos, isso não significa que a solução majoritária seja materialmente mais justa, nem a única verdadeira, devendo-se respeitar o "pensar de outra maneira", o "pensamento alternativo". Em suma, "o pressuposto básico da praticabilidade do princípio maioritário é a ausência de pretensões absolutas de verdade". ${ }^{16}$

A democracia pressupõe convívio entre maioria e minoria, na medida em que o princípio democrático da maioria implica necessariamente no princípio da minoria. Esses grupos devem tolerantemente conviver em um mesmo sistema, sob pena de se estar diante de um regime autocrático, com a imposição de uma única vontade. ${ }^{17}$ A opinião da maioria não pode se tornar definitiva, tendo a minoria o direito de conservar seus ideais, tendo meios de limitar a vontade da maioria, preservando o sistema democrático. A democracia é um processo contínuo de identificação e diferenciação dos indivíduos em relação a valores, expressando conflitos sociais que se confrontam e se processam institucionalmente na esfera política. Enquanto vigorar autêntica democracia, não haverá conflito social degenerando em violência, pois ela contribui para desradicalizar as posições político-ideológicas. ${ }^{18}$

A minoria política desempenha um papel essencial no modelo de divisão de poderes, religando, na estrutura do Estado de Direito, a dimensão liberal desse princípio com os reclames do postulado democrático. A democracia não é mero procedimento de seleção de dirigentes, nem se reduz à identidade entre a vontade da maioria ou da opinião pública com a vontade de todos. A vitória eleitoral não importa "escravidão silenciosa dos derrotados", ao contrário, vem de longe a preocupação de dar vida a verdadeiros estatutos da oposição,

minorias "parlamentares".

${ }^{14}$ KELSEN, Hans. Esencia y valor de la democracia. Granada: Comares, 2002, p. 113.

${ }^{15} \mathrm{~A}$ igualdade política e a regra majoritária são os mais importantes princípios de legitimidade democrática no sistema político (DAHL apudMANZELLA, Andrea. Il Parlamento. Bologna: Il Mulino, 1977, p. 210).

${ }^{16}$ CANOTILHO, José Joaquim Gomes. Direito Constitucional e teoria da Constituição. Coimbra: Almedina, 1999, p. 31 1-312.

17 "Para a ideologia autocrática, o caudilho encarna um valor absoluto; para a democracia, pelo contrário, seu valor não passa de relativo; por isso, não constitui esta um campo abonado para o ideal do caudilhismo, nem, em geral, para o princípio da autoridade. Por natureza, a democracia é uma sociedade que não reconhece pai - a paternidade é o modelo e a experiência primária da autoridade -; aspira a ser no possível, uma sociedade de colaboração entre iguais, sem direções tuteladoras. Seu princípio é a coordenação e sua forma mais primitiva a sociedade entre irmãos do regime do matriarcado. [...] A autocracia, ao contrário, é por natureza uma comunidade patriarcal; não se busca em sua estrutura a coordenação, senão uma relação de superior a inferior, a articulação hierárquica" (KELSEN, Hans. Esencia y valor de la democracia. Granada: Comares, 2002, p. 123).

${ }^{18}$ KELSEN, Hans. Teoria geral do Direito e do Estado. Traduzido por Luis Carlos Borges. São Paulo: Martins Fontes, 2000, p. 411. vol.09, nº. 04, Rio de Janeiro, 2016. pp. 2390-2405 2395 
garantindo-lhe espaços de controle e de crítica, a possibilidade de divulgar suas teses para uma possível vitória eleitoral. Isso é mais do que manter as regras formais do jogo eleitoral, mas controlar o conteúdo delas, garantindo a existência, a voz e a participação da minoria parlamentar na vida política do País. ${ }^{19} \mathrm{O}$ objeto desta investigação, repise-se, cinge-se à identificação de previsões normativas que possam dar suporte aos direitos das minorias parlamentares, entre elas as descortinadas a seguir.

\section{ASPECTOS DA LEGISLAÇÃO BRASILEIRA POTENCIALMENTE PROTETIVOS DAS MINORIAS PARLAMENTARES}

O sistema de representação política que se ancora no princípio majoritário é prejudicial às minorias, não refletindo adequadamente a vontade do eleitorado. Não há dúvida que o sistema proporcional é o que melhor responde à proposta de um Estado democrático, na medida em que estimula a formação de diversos grupos políticos, fomenta o multipartidarismo, reflete a heterogeneidade do corpo eleitoral e dá espaços à representação minoritária. ${ }^{20}$ No Brasil, enquanto a formação do Executivo obedece o princípio majoritário, quase todo o Legislativo, à exceção do Senado Federal, obedece o sistema proporcional para sua formação.

Interessa mais, aqui, pela diversidade e possibilidade que representa, a oposição parlamentar representada, especialmente, no Legislativo "proporcional", aquela presente nas Casas Legislativas brasileiras, ${ }^{21}$ desde as federais até as municipais. Em nosso País, em face do sistema de legitimação popular paralela entre Executivo e Legislativo, não é raro que determinado governo seja apoiado por uma minoria parlamentar. Nessas situações, de oposições parlamentares majoritárias, com a mesma ou até maior contundência se revela necessário o reconhecimento dos diferentes pensamentos nesse cruzamento da maioria executiva com a maioria parlamentar.

Esse contexto é particularmente propício ao surgimento de maiorias e minorias "ocasionais", ou "especiais", com oscilações impostas por decisões exigentes de maiorias qualificadas ou ao sabor da temática do momento. O procedimento de tutela das minorias é estabelecido para resguardar a oposição, normalmente minoritária, embora nem sempre uma minoria será oposição. Isso impõe a necessidade alargada da construção de consensos, de negociações superadoras de impasses (impossíveis de serem previamente catalogados), tendo por

\footnotetext{
${ }^{19}$ SAMPAIO, José Adércio Leite, A Constituição reinventada pela jurisdição constitucional. Belo Horizonte: Del Rey, 2002 , p. 550. ${ }^{20}$ REQUEJO, Paloma. Democracia parlamentaria y principio minoritario: la protección constitucional de las minorías parlamentarias. Barcelona: Ariel Derecho, 2000, p. 37-38.

${ }^{21}$ Passa-se ao largo do exame das previsões do Parlamento do Mercosul, cujas modificações introduzidas no Regimento Interno, em abril de 2014, com a adoção da chamada proporcionalidade atenuada, garantiu maior número de parlamentares aos países com maior população e, em contrapartida, os países de menores bancadas procuraram estabelecer maiores exigências de quórum para as decisões consideradas mais polêmicas, tema que guarda sintonia com a presente abordagem, mas, por desbordar do recorte aqui proposto, ficar para outros ensaios.
} vol.09, no. 04, Rio de Janeiro, 2016. pp. 2390-2405 
pano de fundo a impositiva convivência do princípio majoritário com aquele de tutela da minorias. ${ }^{22}$

A grande tarefa de desenvolver uma adequada normatização para a defesa das maiorias parlamentares compete as próprias casas legislativas, quando da aprovação dos regimentos internos, com eventual auxílio dos tribunais. Os suportes para essa edificação encontram-se nas leis fundamentais federal, estaduais e municipais, parâmetros a iluminar o caminho do legislador e as decisões do julgador, toda vez que chamado para dirimir controvérsias.

No âmbito federal, o desenho estatal alinhavado na Constituição Federal, apresentado já no preâmbulo, no expresso propósito da Assembleia Nacional Constituinte de instituir um "Estado Democrático" (complementado no primeiro artigo, "de Direito"), "destinado a assegurar o exercício dos direitos sociais e individuais, a liberdade, a segurança, o bem-estar, o desenvolvimento, a igualdade e a justiça como valores supremos de uma sociedade fraterna, pluralista e sem preconceitos, fundada na harmonia social e comprometida, na ordem interna e internacional, com a solução pacífica das controvérsias...", indica um modelo só possível de ter vida em um sistema democrático que, imperativamente, reconheça e respeite minorias.

Abrindo a normatização constitucional, os "princípios fundamentais" acolhem como fundamento republicano "o pluralismo político", ${ }^{23}$ acrescido, adiante, pela liberdade de criação, fusão, incorporação e extinção de partidos políticos, resguardando-se "a soberania nacional, o regime democrático, o pluripartidarismo, os direitos fundamentais... ${ }^{24}$ Nessas diretrizes, evidente a defesa das minorias, pois só haverá pluripartidarismo se houver partidos minoritários, e o regime democrático pressupõe o reconhecimento da pluralidade política composta por grupos majoritários e minoritários, até para evitar discriminações arbitrárias (combatidas do início ao fim do texto constitucional) e dar vida ao princípio da igualdade.

O constituinte foi além, ao exigir a presença dos líderes das minorias do Senado e da Câmara, na composição do Conselho da República, ${ }^{25}$ ao lado de assegurar, na composição das Mesas e das Comissões, "a representação proporcional dos partidos ou dos blocos parlamentares que participam da respectiva Casa", ${ }^{26}$ reafirmando essa diretriz mesmo durante o recesso, quando haverá a manutenção de uma Comissão representativa do Congresso Nacional cuja composição respeitará "a proporcionalidade da representação partidária”. ${ }^{27}$

\footnotetext{
${ }^{22}$ MANZELLA, Andrea. Il Parlamento. Bologna: Il Mulino, 1977, p. 211-214.

${ }^{23}$ Constituição Federal, art. $1^{\circ}$, V. As reproduções legais foram captadas do site oficial da respetiva Casa legislativa, razão pela qual não serão repetidas nas notas seguintes.

${ }^{24}$ Constituição Federal, art. 17.

${ }^{25}$ Constituição Federal, art. 89, IV e V. Cuida-se de um órgão superior de consulta do Presidente da República destinado a se manifestar previamente acerca de medidas de enfrentamento de crises constitucionais, como estado de sítio, estado de defesa, intervenção federal ou outros relevantes para a estabilidade das instituições democráticas.

${ }^{26}$ Constituição Federal, art. 58, $\$ 1^{\circ}$.
} 
$\mathrm{Na}$ leitura do conjunto da obra constitucional, a exigência de maiorias para a adoção de determinadas decisões $^{28}$ traz implícito o reconhecimento da existência das minorias. A história demonstra que, exceto as (minoritárias!) situações de consenso, em todas as demais haverá uma minoria momentaneamente derrotada, mas não ignorada, até por ser inaceitável tanto o arbítrio exercido por um só ditador, quanto aquele imposto por grupos, sendo incompatível com o sistema adotado em solo pátrio a possível existência de "tiranias democráticas". 29

Ainda é possível extrair da previsão acolhedora da "concessão de asilo político" como princípio reitor das relações internacionais brasileiras, ${ }^{30}$ reforçada pelo óbice à "extradição" de estrangeiro acusado por crime político ou de opinião, ${ }^{31}$ ao lado da ampla proteção ao direito de associação, ${ }^{32}$ claras diretrizes de tutela política voltadas às minorias.

Não se olvide de institutos fundamentais de proteção dos minoritários, configurados nas imunidades, com especial relevo para inviolabilidade parlamentar, a proteger a liberdade de opinião, palavra e voto dos Deputados e Senadores, dos Deputados Estaduais e Distritais e dos Vereadores, ${ }^{33}$ estes que pela primeira vez na história de nosso constitucionalismo foram contemplados com a referida garantia. Ora, nada mais contundente de que essa espécie de prerrogativa na proteção das dissidências, embora a natureza, o objeto e o alcance desbordam do objeto aqui focado, ficando aberto a outros ensaios.

Em verdade, constata-se nas previsões genéricas e específicas sobre a matéria, os pilares fundamentais de um "estatuto das minorias parlamentares" solidamente encravados no texto constitucional federal pátrio, em claro alinhamento ao constitucionalismo ocidental romano-germânico, especialmente desenvolvido na Europa e na América Latina.

Simetricamente, espalhando-se pelo território nacional, as Constituições Estaduais reproduzem o modelo federal de proteção das minorias, tanto na formação das mesas diretivas, na estruturação das comissões, em decisões..., ${ }^{34}$ da mesma forma que as Leis Orgânicas Municipais albergam idêntica orientação. ${ }^{35}$

\footnotetext{
${ }^{27}$ Constituição Federal, art. 58, \$4º.

${ }^{28}$ Por exemplo, "dois terços" para autorização do processo e julgamento político do Presidente da República (arts. 52, I, 86), "três quintos" para emendar a Constituição (art. 60, $\$ 2^{\circ}$ ), "maioria absoluta” para a sustação de processo criminal contra membros da Câmara ou do Senado ( $\operatorname{art} .53, \$ 3^{\circ}$ ) e para a aprovação de leis complementares (art. 69), entre outras.

${ }^{29}$ Termo utilizado por COOLEY apudATALIBA, Geraldo. Judiciário e minorias. Revista de Informação Legislativa, Brasília, n. 96, 1987, p. 193.

${ }^{30}$ Art. $4^{\circ}$, inc. X.

${ }^{31}$ Art. $5^{\circ}$, inc. LII.

${ }^{32}$ Art. 50, XVI a XXI.

${ }^{33}$ Respectivamente, art. 53, caput, art. 27, $\$ 1^{\circ}$ e art. 29, inc. VIII, da Constituição Federal.

${ }^{34}$ Consoante expresso na Constituição do RS (Art. 53: "Compete exclusivamente à Assembleia Legislativa, além de outras atribuições previstas nesta Constituição: [...] XXXIII - eleger sua Mesa, respeitando, dentro do possível, os critérios de representação pluripartidária e de proporcionalidade"; Art. 56, \$ 60: "Durante o recesso haverá uma Comissão Representativa da Assembleia Legislativa, eleita na última sessão ordinária do período legislativo, com atribuições definidas no Regimento, cuja composição reproduzirá, quanto possível, a proporcionalidade da representação dos partidos ou dos blocos parlamentares").
} 
Os Regimentos Internos das Casas Legislativas dedicam-se mais extensamente no regramento da matéria. O Regimento da Câmara dos Deputados, por exemplo, assegura a proporcionalidade na composição da mesa, com a participação de ao menos um membro da minoria, ainda que essa não atinja um número mínimo, ${ }^{36}$ a possibilidade de formação de blocos de minoria, ${ }^{37}$ a participação no Colégio dos Líderes, ${ }^{38}$ nas Comissões, ainda que proporcionalmente não the caiba lugar ${ }^{39}$ na Comissão $\mathrm{Geral},{ }^{40}$ nas Comunicações de Lideranças, ${ }^{41}$ entre outras, sendo verdadeiro guia de convivência entre maioria e minoria, com especial preocupação em proteger esta. Semelhantes previsões aparecem no Regimento Interno do Senado Federal, ${ }^{42}$ indicando uma certa harmonia no

${ }^{35}$ Por exemplo, na Lei Orgânica de Santo Ângelo/RS: "Art. 75: A Comissão Representativa é composta de um representante de
cada bancada e do Presidente da Câmara e igual número de suplentes" e na de Porto Alegre: "Art. 53: As deliberações da Câmara
Municipal e de suas Comissões, salvo disposição em contrário nas Constituiçôes Federal e Estadual e nesta Lei Orgânica que
exijam quorum qualificado, serão tomadas por maioria de votos, presente a maioria de seus membros [...]; Art. 58: A Câmara
Municipal terá comissões permanentes e temporárias, constituídas na forma e com as atribuições previstas nesta Lei Orgânica, no
Regimento ou no ato de que resultar sua criação. $\$ 1^{\circ}$ : Na constituição de cada comissão deverá ser observada a representação proporcional dos partidos ou dos blocos parlamentares".

${ }^{36}$ Regimento Interno da Câmara dos Deputados (Res. n. 17, de 1989): "Art. $8^{\circ} \mathrm{Na}$ composição da Mesa será assegurada, tanto quanto possível, a representação proporcional dos Partidos ou Blocos Parlamentares que participem da Câmara, os quais escolherão os respectivos candidatos aos cargos que, de acordo com o mesmo princípio, lhes caiba prover, sem prejuízo de candidaturas avulsas oriundas das mesmas bancadas, observadas as seguintes regras: [...] $₫ 3^{\circ}$ É assegurada a participação de um membro da Minoria, ainda que pela proporcionalidade não lhe caiba lugar".

${ }^{37}$ Dos blocos parlamentares da maioria e da minoria: "Art. 12. As representações de dois ou mais partidos, por deliberação das respectivas bancadas, poderão constituir Bloco Parlamentar, sob liderança comum. [...] Art. 13. Constitui a maioria o Partido ou Bloco Parlamentar integrado pela maioria absoluta dos membros da Casa, considerando-se minoria a representação imediatamente inferior que, em relação ao Governo, expresse posição diversa da maioria. Parágrafo único. Se nenhuma representação atingir a maioria absoluta, assume as funções regimentais e constitucionais da maioria o Partido ou Bloco Parlamentar que tiver o maior número de representantes".

${ }^{38}$ Regimento Interno da Câmara dos Deputados: "Art. 20. Os Líderes da Maioria, da Minoria, dos Partidos, dos Blocos Parlamentares e do Governo constituem o Colégio de Líderes [...] § $2^{\circ}$ Sempre que possível, as deliberações do Colégio de Líderes serão tomadas mediante consenso entre seus integrantes; quando isto não for possível, prevalecerá o critério da maioria absoluta, ponderados os votos dos Líderes em função da expressão numérica de cada bancada".

39 "Art. 23. Na constituição das Comissões assegurar-se-á, tanto quanto possível, a representação proporcional dos Partidos e dos Blocos Parlamentares que participem da Casa, incluindo-se sempre um membro da minoria, ainda que pela proporcionalidade não lhe caiba lugar".

40 “Art. 91. A sessão plenária da Câmara será transformada em Comissão Geral, sob a direção de seu Presidente, para: I - debate de matéria relevante, por proposta conjunta dos Líderes, ou a requerimento de um terço da totalidade dos membros da Câmara [...] \& $1^{\circ}$ No caso do inciso I, falarão, primeiramente, o Autor do requerimento, os Líderes da Maioria e da Minoria, cada um por trinta minutos, seguindo-se os demais Líderes, pelo prazo de sessenta minutos, divididos proporcionalmente entre os que o desejarem, e depois, durante cento e vinte minutos, os oradores que tenham requerido inscrição junto à Mesa, sendo destinados dez minutos para cada um".

${ }_{41}$ “Art. 89. As Comunicações de Lideranças previstas no $\$ 1^{\circ}$ do art. 66 deste Regimento destinam-se aos Líderes que queiram fazer uso da palavra, por período de tempo proporcional ao número de membros das respectivas bancadas, com o mínimo de três e o máximo de dez minutos, não sendo permitido apartes, destinando-se à Liderança do Governo a média do tempo reservado às representações da Maioria e da Minoria”.

${ }^{42}$ Do Regimento Interno do Senado Federal (Res. n. 93, de 1970 e Res. n. 18, de 1989, atualizadas), vale citar: "(Dos Blocos Parlamentares da Maioria e da Minoria e das Lideranç̧as): Art. 65. A maioria, a minoria e as representaçōes partidárias terão líderes e vice-líderes. $\$ 1^{\circ} \mathrm{A}$ maioria é integrada por bloco parlamentar ou representação partidária que represente a maioria absoluta da Casa. $\$ 2^{\circ}$. Formada a maioria, a minoria será aquela integrada pelo maior bloco parlamentar ou representação partidária que se lhe opuser. $\mathbb{\$} 3^{\circ}$. A constituição da maioria e da minoria será comunicada à Mesa pelos líderes dos blocos parlamentares ou das representaçôes partidárias que as compõem. $\$ 4^{\circ}$. O líder da maioria e o da minoria serão os líderes dos blocos parlamentares ou das representações partidárias que as compõem, e as funções de vice-liderança serão exercidas pelos demais líderes das representações partidárias que integrem os respectivos blocos parlamentares. [...] $₫ 5^{\circ} \mathrm{Na}$ hipótese de nenhum bloco parlamentar vol.09, nº. 04, Rio de Janeiro, 2016.pp. 2390-2405 2399 
regular o tema.

No Código de Ética e Decoro Parlamentar da Câmara dos Deputados ${ }^{43}$ vem expressa a preocupação da manutenção da proporcionalidade da representação partidária, disposições também presentes no diploma legal equivalente, instituído pelo Senado Federal. ${ }^{44}$

As diretrizes federais no tratamento do tema aparecem reproduzidas nos Regimentos Internos das Assembleias Legislativas dos Estados federados, como a do Rio Grande do Sul, que contém expressas normatizações protetivas das minorias, na composição de colégios de líderes, ${ }^{45}$ eleição das mesas, ${ }^{46}$ composição das comissões, ${ }^{47}$ comunicações $^{48}$ e outras, ${ }^{49}$ com similares previsões em São Paulo, ${ }^{50}$ diretrizes também

alcançar maioria absoluta, assume as funções constitucionais e regimentais da maioria o líder do bloco parlamentar ou representação partidária que tiver o maior número de integrantes, e da minoria, o líder do bloco parlamentar ou representação partidária que se lhe seguir em número de integrantes e que se lhe opuser."

${ }^{43}$ Res. n. 25, de 2001 (Código de Ética e Decoro Parlamentar da Câmara dos Deputados), exemplificativamente: "Art. 70 O Conselho de Ética e Decoro Parlamentar compõe-se de quinze membros titulares e igual número de suplentes com mandato de dois anos. $₫ 1^{\circ} \mathrm{Na}$ representação numérica dos partidos e blocos parlamentares será atendido o princípio da proporcionalidade partidária [...]. O partido a que pertencer o corregedor designará, como titular, um deputado a menos que o número a que tenha direito com a aplicação do princípio da proporcionalidade partidária".

${ }^{44}$ Res. n. 20/1993 (Institui o Código de Ética e Decoro Parlamentar): "Art. 23. O Conselho de Ética e Decoro Parlamentar será constituído por quinze membros titulares e igual número de suplentes, eleitos para mandato de dois anos, observado, quanto possível, o princípio da proporcionalidade partidária e o rodízio entre Partidos Políticos ou Blocos Parlamentares não representados".

${ }^{45}$ O Regimento Interno da Assembleia Legislativa do RS pontua: (Res. n. 2.288/91): Do Colégio dos Líderes: "Art. 20. Os Líderes de Bancada, Partidários ou do Governo constituem o Colégio de Líderes. Parágrafo único. Sempre que possível, as deliberações do Colégio de Líderes serão tomadas mediante consenso entre os seus integrantes; quando isto não for possível, prevalecerá o critério da maioria equivalente a dois terços, ponderados os votos dos Líderes em função da expressão numérica de cada Bancada".

${ }^{46}$ Eleição da Mesa: "Art. 23. $₫ 1^{\circ} \mathrm{Na}$ composição das chapas serão respeitados, dentro do possível, os critérios de representação pluripartidária e proporcionalidade".

${ }^{47}$ Da Comissão Representativa: "Art. 41. A Comissão Representativa, composta de 11 (onze) membros efetivos e 10 (dez) suplentes, funcionará durante o recesso parlamentar. [...] Art. 42. $\$ 1^{\circ} \mathrm{A}$ composição das chapas reproduzirá, quanto possível, a proporcionalidade de representação das Bancadas". Das Comissões Técnicas Permanentes: "Art. 53. A alteração do número de integrantes de Bancada que importe modificações da proporcionalidade na composição das Comissões somente será considerada no início dos trabalhos da primeira e da terceira sessões legislativas de cada legislatura".

${ }^{48}$ Das Comunicações: "Art. 148. No período de comunicações será assegurada a palavra a 16 (dezesseis) Deputados, obedecendose à proporcionalidade do número de membros de cada Bancada".

${ }^{49}$ Das Disposições Finais: "Art. 282. A Assembleia Legislativa, como membro da União Nacional dos Legislativos - UNALE, farse-á representar nos congressos daquele Órgão por uma Comissão em cuja composição será observado, tanto quanto possível, o critério da proporcionalidade partidária".

${ }^{50}$ Regimento Interno da Assembleia Legislativa do Estado de São Paulo - SP (Ato n. 27/2007, consolidado): "Art. 26 - Assegurarse-á nas Comissões Permanentes e Temporárias, tanto quanto possível, a representação proporcional dos Partidos, a qual se define com o número de lugares reservados aos Partidos em cada Comissão. [...] \& $3^{\circ}-$ Se não houver acordo, o Presidente, de ofício, fará as respectivas nomeações observando, tanto quanto possível, a representação proporcional dos Partidos; Art. 27 - Os membros das Comissões Permanentes e Temporárias serão nomeados por Ato do Presidente da Assembleia, publicado no órgão oficial, mediante indicação escrita dos Líderes de Partido [...] $₫ 1^{\circ}$ - Os Líderes farão a indicação dentro do prazo de 15 dias ... . Decorrido esse prazo sem a indicação, o Presidente da Assembleia nomeará os membros das Comissões imediatamente, observando, tanto quanto possível, a representação proporcional dos Partidos. [...] O membro que deixar o Partido sob cuja legenda tenha sido efetuado o cálculo de proporcionalidade perderá o cargo na Comissão Permanente ou Temporária. $₫ 5^{\circ}$ - As modificações numéricas que venham a ocorrer nas Bancadas dos Partidos que importem modificações da proporcionalidade partidária na composição das Comissões só prevalecerão a partir da sessão legislativa subsequente, salvo se o Partido deixar de ter representante na Assembleia, caso em que a Mesa providenciará imediatamente a redistribuição das vagas; [...] Art. 81 - Constitui a Maioria o Partido ou Bloco Parlamentar integrado pela maioria absoluta dos membros da Casa, considerando-se Minoria a representação vol.09, no. 04, Rio de Janeiro, 2016. pp. 2390-2405 
incorporadas nos Códigos de Ética Parlamentar estaduais. ${ }^{51}$

Mantendo a lógica do sistema, as Leis Orgânicas Municipais também focaram o tema, como a Lei Orgânica de Santo Ângelo, ${ }^{52}$ a de Porto Alegre, ${ }^{53}$ a do Rio de Janeiro, ${ }^{54}$ entre outras. Nesses diplomas locais aparece expressa imposição aos Regimentos Internos para disciplinarem a matéria, tarefa cumprida, consoante se verifica em Porto Alegre, com preocupação especial em assegurar a proporcionalidade na eleição da mesa ${ }^{55}$ e na formação das diversas comissões, ${ }^{56}$ em Santo Ângelo, ${ }^{57}$ no Rio de Janeiro, ${ }^{58}$ com previsões autoexplicativas da

imediatamente inferior que, em relação ao Governo, expresse posição diversa da Maioria. [...] Art. 83 - O Colégio de Líderes, presidido pelo Presidente da Assembleia e composto pelos Líderes dos Partidos, do Governo, da Minoria e dos Blocos Parlamentares, é instância de organização de Ordem do Dia de sessão ordinária e consultiva para outros temas de interesse da Assembleia Legislativa. $₫ 1^{\circ}$ - Por iniciativa do Presidente da Assembleia ou de Líderes que representem maioria absoluta dos membros da Assembleia, o Colégio de Líderes reunir-se-á e decidirá suas posições mediante consenso entre seus integrantes. $\$ 2^{\circ}-$ Quando não for possível o consenso, prevalecerá o critério da maioria absoluta, ponderados os votos dos Líderes de cada Partido em função da expressão numérica de sua Bancada. $\$ 3^{\circ}$ - Os Líderes de Bloco Parlamentar e da Minoria terão assento no Colégio de Líderes com direito a voz, mas não a voto".

${ }^{51}$ RS, Res. n. 2.514, de 30 de novembro de 1993 (Institui o Código de Ética Parlamentar): "Da Comissão de Ética Parlamentar. Art. $8^{\circ}$ É criada a Comissão de Ética Parlamentar, aplicando-se-lhe, quando cabíveis, os preceitos regimentais referentes às Comissões Permanentes. $₫ 1^{\circ}$ Os membros da Comissão de Ética serão indicados pela Mesa, ouvidos os Líderes de Bancadas, e eleitos pelo Plenário para um mandato de 02 (dois) anos". Em São Paulo, a Res. n. 766, de 16.12.1994 (Institui o Código de Ética e Decoro Parlamentar), prevê: "Art. 23 - O Conselho de Ética e Decoro Parlamentar será constituído por 9 (nove) membros titulares e igual número de suplementes, eleitos para mandato de 2 (dois) anos, observado, quanto possível, o princípio da proporcionalidade partidária e o rodízio entre Partidos Políticos ou Blocos Parlamentares não representados".

${ }_{52}$ Embora a regulamentação dessa matéria tenha sido reservada ao Regimento Interno, ainda assim aparece no art. 75: "A Comissão Representativa é composta de um representante de cada bancada e do Presidente da Câmara e igual número de suplentes".

${ }^{53}$ Lei Orgânica do Município de Porto Alegre: "Art. 58 - A Câmara Municipal terá comissões permanentes e temporárias, constituídas na forma e com as atribuições previstas nesta Lei Orgânica, no Regimento ou no ato de que resultar sua criação. $\$ 1^{\circ}$ $\mathrm{Na}$ constituição de cada comissão deverá ser observada a representação proporcional dos partidos ou dos blocos parlamentares".

${ }^{54}$ Lei Orgânica do Município do Rio de Janeiro: "Art. 54 - O regimento interno disporá sobre a composição da Mesa da Câmara Municipal e, subsidiariamente, sobre a sua eleição. $\$ 1^{\circ}$ - Na constituição da Mesa Diretora é assegurada, tanto quanto possível, a representação proporcional dos partidos ou dos blocos parlamentares que participaram da Câmara Municipal. [...] Art. 64 ... $\$ 1^{\circ}$ $\mathrm{Na}$ constituição de cada comissão, é assegurada, tanto quanto possível, a representação proporcional dos partidos ou dos blocos parlamentares que participam da Câmara Municipal. $₫ 2^{\circ}$ - Inexistindo acordo com o cumprimento do disposto no parágrafo anterior, a composição das comissões será decidida pelo Plenário".

${ }^{55} \mathrm{O}$ Regimento Interno da Câmara de Vereadores de Porto Alegre aponta: "Art. 13. $\$ 1^{\circ}$ A Mesa Diretora será eleita pela maioria absoluta dos Vereadores, mediante chapa única ou cargo a cargo, em votação nominal, respeitado o critério da proporcionalidade dos partidos ou dos blocos partidários, para um mandato de um ano".

56 “Art. 33, $\mathbb{1} 1^{\circ}$. Na eleição dos Presidentes e Vice-Presidentes das Comissões Permanentes, assegurar-se-á a representação proporcional dos partidos ou blocos partidários. Art. $58 . \$ 1^{\circ} \mathrm{Na}$ formação das Comissões Especial e Parlamentar de Inquérito, deverá ser observado o seguinte: a) proporcionalidade partidária ou de bloco partidário; [...] Art. 63-A. Poderá ser constituída, por deliberação da Mesa e das Lideranças, mediante Resolução de Mesa, Comissão Especial para avaliar e discutir a implementação do Plano Diretor de Desenvolvimento Urbano Ambiental - PDDUA -, bem como para propor-lhe correções e complementações e relatar projetos que disponham sobre sua alteração. $₫ 1^{\circ}$ A Comissão Especial, constituída, será integrada por 12 (doze) Vereadores, com direito à voz e a voto, respeitada a proporcionalidade dos partidos ou dos blocos partidários, nos termos do art. 58 desta Resolução. Art. 69. A designação dos membros da Comissão Parlamentar de Inquérito caberá ao Presidente da Câmara, ouvidos os Líderes, assegurando-se a representação proporcional partidária ou de blocos partidários. Art. 79. A Comissão Representativa é constituída pela Mesa e demais Vereadores para este fim eleitos, de tal forma a alcançar, no mínimo, a maioria absoluta da Câmara, resguardada a proporcionalidade das representações partidárias. Art. 180. No período destinado a Comunicações, será concedida a palavra por cinco minutos para cada orador, a fim de tratar de assunto de sua livre escolha, sendo permitido apartes. $\$ 1^{\circ}$. Os Vereadores serão distribuídos em seis grupos, respeitando-se a proporcionalidade partidária e a ordem alfabética dos nomes".

${ }^{57}$ Regimento Interno da Câmara Municipal de Santo Ângelo: "Art. 46 - Na constituição das Comissões será assegurada, tanto vol.09, no. 04, Rio de Janeiro, 2016. pp. 2390-2405 2401 
preocupação em preservar as minorias. ${ }^{59} \mathrm{~A}$ amostra dos Municípios traduz o conteúdo que, com tênues diferenças, é reproduzido por todas as Câmaras de Vereadores do Brasil, nesse verdadeiro "copião" nacional, cujas exceções confirmam a regra, que são as Leis Orgânicas das 5.565 comunas pátrias.

\section{CONSIDERAÇÕES FINAIS}

A partir do exposto, é possível afirmar que, no Brasil, há suporte normativo suficiente para se edificar um "estatuto das minorias" parlamentares, verticalmente reproduzido, na medida em que prevê garantias mínimas de proteção à atuação dos grupos minoritários presentes desde o Senado até as Câmaras de Vereadores. Em uma espécie de entrelaçamento, como o cântico dos galos eternizados por João Cabral de Melo Neto, em seu "Tecendo a manhã", a teia legislativa nacional, une-se a estadual e a municipal, encorpando-se na sustentação de

quanto possível, a proporcionalidade das Representações Políticas existentes na Câmara. Art. 76 - $\$ 1^{\circ}$ - As Comissões Especiais serão compostas de três membros, salvo expressa deliberação em contrário da Câmara ou disposição legal ou regimental. \ 20Ouvidos os Líderes de Bancadas e, observada a proporcionalidade partidária, cabe ao Presidente da Câmara dar posse aos Vereadores que devem constituir essas Comissões. Art. 80 - A Comissão Representativa será constituída pelo Presidente e pelo Primeiro Secretário da Mesa e, um representante de cada Bancada existente na Câmara e de igual número de suplentes e terá as atribuições constantes dos artigos 74,75 e 76 da Lei Orgânica do Município".

${ }^{58}$ Regimento Interno da Câmara de Vereadores do Município do Rio de Janeiro: "Art. $4^{\circ}$ - Sob a presidência do Vereador mais votado na direção dos trabalhos, e observando o disposto nos arts. 25 e 26, passar-se-á à eleição da Mesa Diretora que dirigirá os trabalhos da Câmara Municipal por duas sessões legislativas. $\$ 1^{\circ}$ - Na constituição da Mesa Diretora, nessa e nas demais eleições, será assegurada, tanto quanto possível, a representação proporcional dos partidos ou dos blocos parlamentares que participarem da Câmara Municipal. Art. 59 - A composição das comissões permanentes será feita de comum acordo pelos líderes, assegurando-se, tanto quanto possível, a representação proporcional dos partidos ou dos blocos parlamentares. Parágrafo único - Na constituição das comissões permanentes, para efeito de composição, figurará sempre o nome do Vereador efetivo ainda que licenciado. Art. 60 Não havendo acordo, proceder-se-á a escolha dos membros das comissões permanentes por eleição da Câmara Municipal, votando cada Vereador em um único nome, para cada comissão, considerando-se eleitos os mais votados. $\$ 1^{\circ}$ - Proceder-se-á a tantos escrutínios quantos forem necessários para completar o preenchimento de todos os lugares de cada comissão. $₫ 2^{\circ}$ Havendo empate, considerar-se-á eleito o Vereador do partido que resguardar a proporção partidária ou de bloco parlamentar. [...] Art. 117 - Ao Presidente da Câmara Municipal caberá designar, mediante indicação das lideranças, os Vereadores que comporão a comissão, assegurando-se, tanto quanto possível, a representação proporcional dos partidos e blocos parlamentares".

${ }^{59}$ No Rio de Janeiro, o Precedente Regimental n. 20, inicia com (entre outras) as seguintes afirmativas: "Considerando que a Carta Magna consagrou o direito ao exercício da franquia democrática do mecanismo de controle, fiscalização e investigação de fatos determinados, assegurando na constituição das Comissões Parlamentares de Inquérito o direito das minorias parlamentares; Considerando que se infere nesse princípio constitucional a garantia da participação do signatário proponente da constituição da Comissão Parlamentar de Inquérito, independentemente da representação numérica da bancada ou bloco parlamentar a que esteja vinculado; Considerando que as Comissões Parlamentares de Inquérito constituem órgãos colegiados e que, além de resguardar o direito de participação de quem a requereu, também deve obedecer ao critério da proporcionalidade partidária, que deflui o art. 59 do Regimento Interno, observando-se as indicações das lideranças; Considerando que o Regimento Interno da Câmara Municipal do Rio de Janeiro apresenta lacunas que causam empecilhos ao discernimento para a composição das Comissões Parlamentares de Inquérito; Considerando que cumpre ao Presidente estabelecer Precedentes Regimentais, a fim de orientar os trabalhos da Edilidade e permitir o bom andamento das atividades legislativas [...]"; Na mesma trilha, o Precedente Regimental n. 33: "Considerando a decisão do Supremo Tribunal Federal no julgamento do Mandado de Segurança n. 24849-DF, em 22 de junho do ano corrente, assegurando à parte impetrante o direito à efetiva instauração da Comissão Parlamentar de Inquérito - 'CPI dos Bingos'; Considerando que aquela decisão do Órgão Máximo da Magistratura Nacional deferiu ao Presidente da Mesa Diretora do Senado Federal a atribuição de proceder à designação dos nomes dos Senadores para compor a CPI nas vagas deixadas sem indicação pelas respectivas Lideranças que detinham a proporcionalidade partidária; Considerando a consagração do princípio constitucional que garante à minoria legislativa a instauração do inquérito parlamentar, balizado no art. $58, \$ 3^{\circ} \mathrm{da}$ Constituição da República [...]”. 
um modelo de democracia da convivência entre maiorias e minorias parlamentares. Enquanto suas linhas mestras estão fixadas nas Leis Mães dos entes federados (Constituição Federal, Constituições Estaduais e Leis Orgânicas do Distrito Federal e Municípios pátrios), seu generoso enraizamento ocorre nos Regimentos Internos de todas as Casas Legislativas nacionais.

Como normalmente as minorias exercem o papel de oposição, é bom reforçar "suas posições" nos períodos democráticos, firmando lastro de resistência às possíveis tentativas (tentações!?) de retorno ao autoritarismo, das quais nenhuma sociedade se encontra completamente livre. Sempre é tempo de aprender, e espelhados nas marchas e contramarchas de nossa história política, tomara que tenhamos a sabedoria de cultivar uma democracia avessa a retrocessos.

Além do sempre possível controle social, popular, sobre essa partilha de espaços políticos, compete aos próprios parlamentares, de forma madura, o estabelecimento de normas (respeitando-as) que espelhem, tanto quanto possível, a pluralidade das faces (multiculturais) da sociedade brasileira, ou os vários "brasis" insertos no Maior. Ademais, a tarefa de garantia da oposição, em Estados Democráticos, também é do Poder Judiciário, formado por membros independentes, vitalícios, inamovíveis, descompromissados com possíveis maiorias parlamentares justamente para frear interesses poderosos, quando isso se mostrar necessário. Mas a função do Judiciário, nesse tema, fica para outras aventuras....

Em suma, zelar pela sobrevivência de uma oposição com direitos mínimos é cuidar da manutenção da democracia, e a grande árvore normativa de sustentação desse mister nasceu em Brasília, em 1988, produziu mudas plantadas nos Estados Membros e no Distrito Federal, em 1989, e nos municípios em 1990, e a tarefa de manejo, para que elas sejam frondosas e frutíferas, compete a cada brasileiro que se pensa democrático e que deseja viver à luz de um sistema democrático.

\section{THE PROTECTION OF BRAZILIAN PARLIAMENTARY MINORITIES AS A MEANS OF PROMOTING DEMOCRACY}

\section{Summary}

The history of the Western Parliament has in respect of the majority with minorities one of their key features and at the same time, an inexhaustible source of friction. There is no doubt that democracy stands on a majority vote, but it takes constant vigilance to combat the dangers of majorities, preventing them from becoming tyrannical, as well as acting stifle disagreements and prevent the emergence and strengthening of new ideas, eventually representing social minorities. Numerous legislative passages, present in all Brazilian states spheres, in the Union, the States, the Federal District and the municipalities, guarantee performance spaces of parties and minority groups in democratic proposal that the present article, from samples, emphasizes. In short, Brazil has enough to protect the work of the parliamentary minority, present since the Municipal Council to the Senate legislative basis, but it is essential that the law has projection in real life because protect these minorities is ultimately preserve 
democracy, keeping the horizon Shining Path's democratic future ...!

Keywords: Parliament. Democracy. Parliamentary minorities.

\section{BIBLIOGRAFIA}

APPIO, Eduardo. Direito das minorias. São Paulo: Revista dos Tribunais, 2008.

ATALIBA, Geraldo. Judiciário e minorias. Revista de Informação Legislativa, Brasília, n. 96, 1987.

ATIENZA, Manuel. El sentido del Derecho. Barcelona: Ariel, 2003.

BERNAL PULIDO, Carlos. El principio de proporcionalidad y los Derechos Fundamentales. Madrid: Centro de Estudios Políticos y Constitucionales, 2005.

BIGLINO CAMPOS, Paloma. Los vicios en el procedimiento legislativo. Madrid: Centro de Estudios Constitucionales, 1991.

BOBBIO, Norberto. A era dos Direitos. Rio de Janeiro: Campus, 1992. El futuro de la democracia. Revista de las Cortes Generales, Madrid, n. 2, 1984.

CANOTILHO, José Joaquim Gomes. Constituição dirigente e vinculação do legislador: contributo para a compreensão das normas constitucionais programáticas. Coimbra: Coimbra, 1994.

Direito Constitucional e teoria da Constituição. Coimbra: Almedina, 1999.

DAMATTA, Roberto. Carnavais, malandros e heróis: para uma sociologia do dilema brasileiro. Rio de Janeiro: Rocco, 1997.

GARCÍA MORILLO, Joaquín; El parlamento en la era global. Cuadernos de Derecho Publico, Madrid, n. 1, 1997.

KELSEN, Hans. A Democracia. São Paulo: Martins Fontes, 2000.

O que é Justiça? 3. ed. São Paulo: Martins Fontes, 2001.

Esencia y valor de la democracia. Granada: Comares, 2002.

Teoria geral do Direito e do Estado. Traduzido por Luis Carlos Borges. São Paulo: Martins Fontes, 2000.

MANZELLA, Andrea. Il Parlamento. Bologna: Il Mulino, 1977.

OLIVEIRA, Marcelo Andrade Cattoni de. Comentários à Constituição do Brasil (Org. CANOTILHO, J. J. Gomes, et al). São Paulo: Saraiva/Almedina, 2014.

REQUEJO, Paloma. Democracia parlamentaria y principio minoritario: la protección constitucional de las minorías parlamentarias. Barcelona: Ariel, 2000.

SAMPAIO, José Adércio Leite. A Constituição reinventada pela jurisdição constitucional. Belo Horizonte: Del Rey, 2002. 
VERONESE, Osmar. Constituição: reformar para que(m)? Porto Alegre: Livraria do Advogado, 1999. Inviolabilidade parlamentar: do senador ao vereador. Porto Alegre: Livraria do Advogado, 2006.

ZAGREBELSKY, Gustavo. El Derecho dúctil. Ley, Derechos, Justicia. Traduzido por Marina Gascón. Madrid: Trotta, 2003.

Le immunità parlamentari. Natura e limiti de una garanzia constituzionale. Turin: Einaudi, 1979.

Trabalho enviado em 26 de novembro de 2015.

Aceito em 05 de março de 2016. 